\title{
História da ética em pesquisa com seres humanos
}

DOI: 10.3395/reciis.v2.Sup1.203pt

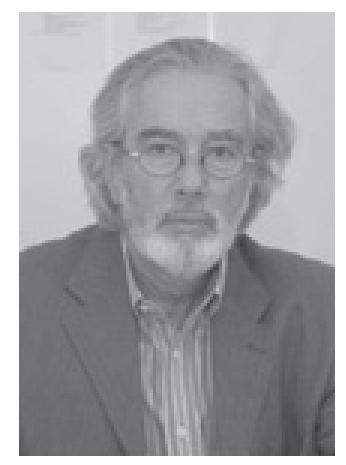

Miguel Kottow

Universidade do Chile, Santiago, Chile

kottow@terra.cl

\section{Resumo}

Este artigo contextualiza o surgimento do campo da ética em pesquisa em eventos históricos, sociais e políticos dos últimos 60 anos. Faz uma distinção entre ética profissional e bioética, focalizando os antecedentes históricos e filosóficos do campo da bioética. Situa ainda o surgimento da ética em pesquisa como resultado da divulgação de condutas impróprias na prática científica, discutindo as primeiras normas sobre ética em pesquisa, as diretrizes contidas no Relatório Belmont e sua influência sobre a elaboração da teoria bioética principialista. Analisa também o funcionamento dos comitês de ética em pesquisa e as possíveis limitações à atividade científica. Por fim, pontua alguns temas que continuam pendentes, como o pagamento aos participantes dos estudos, a realização de pesquisas com pessoas inconscientes, a utilização de crianças em experimentos para testes de novos medicamentos ou novas indicações terapêuticas, a definição de risco mínimo e a forma como se tem dado a bioética em países em desenvolvimento.

\section{Palavras-chave}

história da ética; bioética, ética em pesquisa; ética profissional; teoria principialista

\section{Introdução}

A importância de uma resenha histórica reside mais no desenvolvimento de conceitos do que na cronologia de eventos. Em uma evolução tão veloz como a da ética em pesquisa com seres humanos, as mudanças ocorrem de forma fluida e não permitem estabelecer períodos de tempo claramente delimitados. Em relação a esse tema, não é possível falar em progresso, uma vez que não há um caminho traçado em direção a uma meta. Algumas conquistas éticas iniciais, como o respeito pelas pessoas ou a proposta de uma justiça sanitária, têm se modificado vagarosamente. Essa é uma observação de fundamental importância para o Hemisfério Sul, onde as injustiças e desigualdades são endêmicas e progressivamente severas. Uma bioética feita na América Latina tem que lutar, desde sua trincheira, pelo resgate dos que não têm poder e pela proteção das populações empobrecidas (Kottow 2006).

Alaistar MacIntyre (1984) observa que as práticas sociais produzem bens externos quantificáveis e negociáveis e bens internos relacionados com a excelência e a ética do desempenho. A ética em pesquisa, a rigor a 
do pesquisador, é uma ética profissional que distingue atuações corretas de incorretas, geralmente com base em um código explícito. Os aspectos fundamentais se referem à probidade de não adulterar as diversas etapas da pesquisa, não manipular os resultados nem sua publicação, respeitar as participações e prioridades dos pares, não plagiar, lidar com dinheiro com honestidade e transparência, e não se apropriar de bens materiais ou intelectuais. Todos esses aspectos dizem respeito à integridade do trabalho científico e à confiabilidade dos bens externos produzidos, diferindo apenas em detalhes específicos das exigências morais vigentes em outras profissões. As transgressões ao código profissional são analisadas pelos pares e, eventualmente, pelos superiores institucionais, sendo avaliadas na ante-sala da bioética.

A bioética pressupõe que o comportamento profissional está sob controle, preferindo se preocupar com as relações estabelecidas entre o profissional e os indivíduos ou comunidades em que se aplicam as práticas assistenciais e científicas. No caso da pesquisa com seres humanos, a ênfase da bioética estará nos efeitos que o projeto desenhado pelo pesquisador terá sobre os participantes. A função prioritária da ética em pesquisa é proteger o participante, um indivíduo que se submete voluntariamente a um risco, vivenciando com freqüência condições de vulnerabilidade ou por razões sociais - pobreza, subnutrição, falta de poder - ou por ser portador de doenças que podem ou não ser o motivo de seu recrutamento para o estudo. A probidade científica exigida pela ética profissional se subordina à transparência e sustentabilidade da relação pesquisador-participante propiciada pela bioética. $\mathrm{O}$ item 5 da introdução da Declaração de Helsinque (2000) assinala que o bem-estar dos participantes da pesquisa deve prevalecer sobre os interesses da ciência e da sociedade, ou seja, os bens internos protegidos pela bioética terão prioridade sobre os bens externos ponderados pela ética profissional.

A distinção entre a ética profissional e a ética em pesquisa tem especial relevância por causa das polêmicas suscitadas na atualidade entre pesquisadores dispostos a aumentar os riscos assumidos pelos participantes por razões puramente científicas - o uso de placebos ou submedicações, por exemplo - e a ética em pesquisa, que protege os sujeitos incluídos em estudos e coloca em dúvida a estrita utilidade de tanto rigor científico. A polêmica ganha nova força nas discrepâncias entre a medicina baseada em evidências e as reticências éticas e práticas desencadeadas. Não obstante, há situações híbridas em que as transgressões à ética profissional interessam à bioética por produzirem danos aos participantes ou à sociedade, como acontece quando os pesquisadores omitem efeitos prejudiciais dos medicamentos estudados.

Um caso paradigmático é o da pesquisadora Nancy Olivieri, que revelou dados negativos acerca do medicamento deferiprone, que ela mesma estava estudando, contrariando os interesses e as instruções do laboratório patrocinador e de sua própria universidade. Sua integridade ética foi questionada por pesquisadores que não tinham escrúpulos em cometer transgressões, fazendo uma ciência imprópria e imoral. O conflito tem sido resumido como o contraste entre os valores da ciência e os valores da grande empresa; porém, quando falha a integridade dos cientistas, ocorre uma conspiração entre ciência e empresa que se volta contra a bioética protetora dos pacientes e participantes (Schafer 2004, 2007).

Este artigo contextualiza o surgimento do campo da ética em pesquisa em eventos históricos, sociais e políticos dos últimos 60 anos. Faz uma distinção entre ética profissional e bioética, focalizando os antecedentes históricos e filosóficos do campo da bioética. Situa ainda o surgimento da ética em pesquisa como resultado da divulgação de condutas impróprias na prática científica, discutindo as primeiras normas sobre ética em pesquisa, as diretrizes contidas no Relatório Belmont e sua influência sobre a elaboração da teoria bioética principialista. Analisa também o funcionamento dos comitês de ética em pesquisa e as possíveis limitações à atividade científica. Por fim, pontua alguns temas que continuam pendentes, como o pagamento aos participantes dos estudos, a realização de pesquisas com pessoas inconscientes, a utilização de crianças em experimentos para testes de novos medicamentos ou novas indicações terapêuticas, a definição de risco mínimo e a forma como se tem dado a bioética em países em desenvolvimento.

\section{Antecedentes históricos}

A ciência moderna, iniciada com os experimentos de Galileu (1564-1642) e a entusiasmada aprovação de Francis Bacon (1561-1626), manteve durante muito tempo a certeza de ser uma atividade objetiva, benéfica para a humanidade - na medida em que promove o conhecimento - e eticamente neutra - na medida em que apenas valores morais relacionados a uma prática correta devem ter importância. Equivocadamente Max Weber (1864-1920) é citado para fundamentar essa tese da neutralidade moral da ciência, quando na verdade ele defendeu que a ciência recebe da sociedade o encargo de solucionar determinados problemas, sendo seus resultados aplicados segundo prioridades também sociais. Esses dois momentos sociais, aquele que recorre à ciência e aquele que utiliza seus resultados, estão subordinados a ponderações de valores e são, portanto, eminentemente éticos. Weber insistia que era necessário afastar o método científico propriamente dito de toda influência subjetiva, a fim de pesquisar de forma moralmente neutra, sem vieses nem distorções.

No decorrer do século XX, a expansão tecnocientífica alcançou proporções tais que o método científico não podia ser aplicado sem se ponderar a relação entre benefícios e riscos. Isso adquiriu especial importância em pesquisas biomédicas em que o estudo com seres vivos poderia produzir danos irreversíveis ou até a morte. Resistentes à avaliação ética, os cientistas contemporâneos ainda se opõem à introdução de uma ética em pesquisa empenhada em estabelecer normas morais especialmente relacionadas com a proteção das pessoas e comunidades envolvidas em estudos científicos. A história reconhece, contudo, que desde muito tempo já estava presente a 
reflexão ética sobre os estudos de cadáveres e de seres vivos tantos humanos como não-humanos.

André Vesalio (1514-1564) quebrou o tabu teológico e moral de estudar a anatomia humana por meio de cadáver para refutar os ensinamentos de Galeno (129-199), que acreditava que a dissecção de porcos e macacos lhe daria informações fidedignas sobre a morfologia interna do ser humano. A dissecção anatômica do cadáver humano somente foi oficialmente autorizada por Clemente VII, em 1537, uma vez que fazê-lo anteriormente era considerado um sacrilégio, a menos que se tratasse de um homem e, possivelmente, de um criminoso. $\mathrm{O}$ valor e a certeza do conhecimento residiam no estudo teológico e não na observação natural, a qual era menos estimada. Com o auge da pesquisa experimental em animais não-humanos desde o século XVII - com Harvey, Hales e Hooke -, surgiu também a reflexão ética mais sistemática, sob a forma da controvérsia entre os vivisseccionistas e os opositores a essa prática. A controvérsia foi se intensificando até o século XIX, quando se criaram as primeiras Sociedades de Proteção aos Animais, ao mesmo tempo em que o campo científico defendia a experimentação em seres vivos não-humanos, com o apoio de figuras como Virchow e Bérnard.

Um fenômeno característico dessa época foi a autoexperimentação: Sertürner estuda em si mesmo os efeitos da morfina, Hunter se auto-inocula material extraído de um cancro luético, Davy inala óxido nitroso para conhecer suas propriedades, Auzias se vacina com baixas doses de material sifilítico, e o pitoresco Brown-Séquard menciona em suas palestras que aos 72 anos conseguiu rejuvenescer com auto-administrações de extrato testicular de porquinho-da-índia e cachorro. Não faltaram críticos argumentando que colocar o próprio pesquisador em risco era tão inaceitável como lesar outras pessoas.

Os primeiros vislumbres da participação do paciente em suas decisões clínicas se deram em 1914, quando se considerou ilícito e punível invadir cirurgicamente o corpo de uma pessoa sem seu prévio consentimento. Essa doutrina somente encontrou reforço jurídico com a introdução, em 1957, da expressão "consentimento informado" para situações clínicas, o que já havia ocorrido dez anos antes nas pesquisas envolvendo seres humanos. Os estudos com humanos foram praticados com crescente assiduidade, mas os pesquisadores não se sentiam obrigados a realizar uma reflexão ética específica para sua atividade.

Pierre-Charles Bongrand apresentou em sua tese de doutorado (1905) uma extensa lista de experimentos e auto-experimentos biomédicos em seres humanos, chegando à conclusão de que, em prol da ciência, esses estudos, ainda que "imorais", eram "ocasionalmente necessários”. Sob condições controladas, justificava-se submeter a riscos de pesquisa os "idiotas", os moribundos, os prisioneiros e os condenados à morte, mas não as pessoas vulneráveis, como os pobres, as crianças e as mulheres grávidas. Mencionando o consentimento voluntário e a necessidade de compensações, Bongrand terminou por reconhecer na sociedade um estado de "plácida ignorância" que deveria ser modificado (Amiel et al. 2001). Teceu um entusiasmado elogio à pesquisa intra-hospitalar, em que uma pessoa doente não deve ser vista como um animal de laboratório, mas também não está tão isolada em sua "glória humana" que possa se eximir de participar de estudos que trarão saúde para ela e para outros inumeráveis seres humanos.

\section{Antecedentes filosóficos}

A pesquisa com seres humanos como procedimento estabelecido é muito recente, podendo-se mesmo afirmar que, até o final do primeiro terço do século XX, não havia motivos considerados urgentes para se dedicar reflexão moral a essa prática tão incipiente. A modernidade tem seguido exacerbando sua confiança na racionalidade e no positivismo científico, celebrados em seus primórdios por Francis Bacon e mais recentemente por Spengler e Hottois. A ética em pesquisa científica se nutre melhor dos céticos, que vêem no progresso tecnocientífico uma fonte de riscos para a adaptação do ser humano ao seu ambiente natural e social, bem como para a sobrevivência da humanidade.

O mais conhecido dos críticos à expansão tecnocientífica foi Hans Jonas, precedido pelos escritos de Günther Anders, que têm uma visão puramente pessimista e carente de proposições éticas, apontando uma lacuna intransponível entre as conquistas prometéicas da expansão instrumental e a pobreza emotiva de enfrentá-la com imaginação, antecipação, arrependimento e responsabilidade. À medida que o processo se acelera, o ser humano se converte em um agente produtor, com a conseqüente atrofia da dimensão ética que poderia ajuizar e eventualmente limitar seus afãs pragmáticos (Anders 2002). Hans Jonas (1984) prefere transformar sua crítica em um apelo ético à responsabilidade dos cientistas em redimensionar sua atividade e não expandi-la a zonas de riscos desconhecidos e ameaçadores para futuras gerações. Jürgen Habermas (2001), que havia desenvolvido a idéia de uma razão instrumental que confunde meios e fins, imersa em um pragmatismo avassalador que coloniza a razão comunicativa, tem levado muito recentemente seus conceitos a uma análise crítica da genética e seus riscos para a essência do humano.

Nenhuma dessas abordagens filosóficas da hegemonia da biotecnociência teve impacto direto sobre a ética em pesquisa científica, mas elas têm servido para demonstrar que a ciência não é absolutamente imune a considerações éticas e de relevância social. À medida que se aproxima de conhecer e modificar a biologia humana, a biomedicina ganha importância, assim como a reflexão antropológica que se encontra por trás do texto de Habermas e em escritos de Ronald Dworkin (2000).

\section{O despontar da ética em pesquisa}

O que foi dito até aqui não se contradiz com o surgimento visível e explícito de uma preocupação ética com a pesquisa envolvendo seres humanos a partir dos julgamentos de Nurembergue. Nessa ocasião, foram julgados criminosos da Segunda Guerra Mundial, entre 
os quais se encontravam alguns médicos que tinham protagonizado ou participado de torturas disfarçadas de pesquisa. Hans-Martin Sass (1983) apresenta situações ainda anteriores à guerra, como a de uma circular emitida pelo Ministério da Saúde alemão em 1931, um documento que regulamentava, de forma muito ávida e contemporânea, as "novas terapias e experimentação humana", abordando a vontade do participante, a diferença entre ensaios terapêuticos e não-terapêuticos e a responsabilidade do médico como pesquisador e como terapeuta. O esquecimento cultural e legal no qual recaiu essa norma do Terceiro Reich contrasta penosamente com outra publicação da época, que introduziu com sucesso o conceito de "vidas indignas de serem vividas" e o tornou a base do genocídio, dos campos de concentração e das torturas médicas que caracterizaram esse período (Binding et al. 1920).

A publicação que mais teve impacto no período imediatamente após a guerra foi um livro elaborado por Alexander Mitscherlich e Fred Mielke (1978). A obra documenta e comenta os julgamentos de Nurembergue a que foram submetidos os médicos que tinham sacrificado vidas humanas para conhecer os limites de tolerância a condições extremas, como hipotermia, déficit de oxigênio e injeção massiva de germes patogênicos. Em uma afirmação cuja força reside precisamente em sua tautologia, Andrew Conway Ivy denominou os experimentos criminosos de crimes. Como especialista participante dos julgamentos dos médicos nazistas, Ivy (1977) deixou-se envolver em uma discussão na qual os crimes médicos tentavam ser justificados, senão perdoados, como manifestações de uma ética excepcional que vigorava em tempos de guerra. Essa intromissão de argumentos éticos em situações de criminalidade e genocídio cobraria seus perniciosos dividendos em princípios do século XX, quando proliferaram as análises bioéticas em favor de participações médicas em assuntos militares e de torturas (Kottow 2006).

Dos horrores revelados nesses julgamentos nasceu o Código de Nurembergue, que também representa uma ruptura histórica. Ainda que esse documento tenha sido engatilhado pelos acontecimentos desvelados, não se refere a eles, mas à conduta que um pesquisador científico deve seguir. É uma demonstração de sabedoria que esse primeiro código de ética em pesquisa tenha evitado aludir a situações altamente anômalas e preferido se concentrar em normas éticas gerais e válidas para toda pesquisa. Ainda assim, não deixa de chamar a atenção o fato de um julgamento de criminosos de guerra ter inspirado um código de ética em pesquisa.

Deixando de lado a avaliação habitual de Nurembergue e sem negar sua importância como fundamento de toda reflexão posterior em torno da ética em pesquisa, algumas percepções importantes a esse respeito merecem ser mencionadas. As pessoas que elaboraram o Código de Nurembergue, como foi o caso do estadunidense Ivy, que coordenou o processo, estavam imbuídas de uma alta estima pela autonomia individual. Por isso enfatizaram a livre vontade de participar de experimentos, sem que pudessem admitir que a falha ética fundamental das barbáries médicas não havia sido a ausência de consentimento, mas sim a destruição incompreensível de outro ser humano.

É de se notar que os dez pontos do código tomem o especial cuidado de proteger os participantes, de justificar a relevância social dos estudos e de realizá-los com idoneidade. O primeiro parágrafo refere-se ao "consentimento voluntário", ocupando quase tanto espaço quanto todos os demais parágrafos juntos. Não bastava ratificar a livre vontade de participação daquele momento em diante; devia haver a garantia de que uma sociedade não voltaria a perder a orientação moral ao ponto de se corromper e cometer as maldades do nacional-socialismo. A ética em pesquisa não fica suficientemente presente com um consentimento livre e esclarecido robusto, sendo necessário, além disso, assegurar uma sociedade respeitosa dos direitos humanos (Burt 1996). Segundo essa análise, a conclusão implícita em Nurembergue é de que a liberdade individual tem que se dar em um clima de confiança perante as instituições sociais, incluindo o mundo científico.

Alexander Mitscherlich sempre falou de medicina sem humanidade, de crueldade, de ruptura cultural, mas não de pesquisa científica. Assim também o entendeu o Tribunal de Nurembergue, que emitiu condenações à morte e a prisões prolongadas, o que corresponde a delitos graves e não a imoralidades científicas. A distinção é fundamental, já que ocasionalmente se recorre à desculpa de que as imprudências detectadas em pesquisas biomédicas pela ética são insignificantes em comparação com o ocorrido na Alemanha, uma desculpa inválida por contrastar categorias incomparáveis - uma da área da violação flagrante de direitos humanos, e outra em relação a atividades científicas.

\section{Conduta imprópria na ética científica}

Equivocam-se os cientistas quando alegam que o controle ético da pesquisa não é necessário, já que as imoralidades teriam se produzido unicamente em situações sociais anômalas, como a ditadura nacional-socialista da Alemanha (1933-1945). Essa opinião é facilmente refutável ao se relembrar que a infâmia científica de Tuskegee Valley começou em 1932 e que somente a partir da segunda metade do século XX se passaram a detectar sistematicamente as transgressões éticas a que está suscetível a atividade científica, amparadas pelo vácuo normativo que existiu durante os quase vinte anos que separam Nurembergue e Helsinque.

O fim da Segunda Guerra Mundial marcou também o início da Guerra Fria e da ameaça sentida como muito real de uma iminente terceira conflagração mundial, com o que se pôs especial ênfase em estudar as chamadas armas $\mathrm{ABC}$ - atômicas, biológicas e químicas - e seus efeitos em seres humanos. O controle ético dessas pesquisas foi discutido em nível governamental e militar, em alguns casos se adotando o Código de Nurembergue, e em outros se preferindo a liberdade de flexibilizar as normas e delineá-las ad hoc para cada projeto (Moreno 1996). Quarenta anos mais tarde, persiste a ambigüidade, 
ao ponto de um Comitê Consultivo para Experimentos sobre Radiação Envolvendo Seres Humanos convocado em 1964 ter detectado falhas éticas de transparência, proteção e compensação aos participantes das numerosas pesquisas realizadas por ou para instituições governamentais (Faden 1996).

Menos conhecido na literatura biomédica é o debate suscitado em torno do experimento delineado pelo psicólogo Stanley Milgram para estudar a obediência, o qual era apresentado aos voluntários como uma pesquisa sobre "estudo e aprendizagem". Os participantes ficavam em uma cabine onde controlavam um console de interruptores que supostamente ativavam correntes elétricas de 15 a 450 volts, a serem aplicadas sobre uma pessoa sentada numa poltrona separada do participante por uma parede transparente. O participante devia formular perguntas de associações verbais e punir as respostas incorretas com descargas elétricas que, conforme incitava o pesquisador, fossem de crescente intensidade. O sujeito na poltrona se contorcia com cada descarga e caía inerte com as mais potentes, sem que o participante soubesse que não havia eletricidade efetiva e que as reações eram simuladas. $\mathrm{O}$ experimento terminava se o participante se negava a aumentar a potência das descargas ou se chegava a aplicar as mais potentes, supostamente letais. Milgram (1963) observou que $60 \%$ dos participantes haviam obedecido às instruções do pesquisador e chegado a aplicar as doses máximas, supostamente mortais, de eletricidade, uma descoberta que foi considerada muito significativa na literatura psicológica.

As críticas ficaram mais severas imediatamente depois de publicados os Estudos Comportamentais sobre Obediência, primeiramente reclamando que os participantes haviam sido recrutados sob engano e sem um processo devido de consentimento informado, o que não é raro em ciências sociais, em que se busca a reação espontânea e ingênua do participante. ${ }^{1}$ Em segundo lugar, considerou-se que os sujeitos haviam sido lesionados psicologicamente ao reconhecer que sua vontade podia ser atendida até o ponto de prejudicar gravemente ou mesmo matar uma pessoa em obediência a solicitações peremptórias. O caso deixa uma diversidade de ensinamentos, sendo o principal o fato de que as ciências sociais não se eximem das exigências éticas que se reconhecem nas disciplinas biomédicas. Qualquer intervenção que envolva seres humanos ou que possa afetá-los deve ser analisada e acompanhada por um comitê de ética, uma vez que uma pesquisa ou a divulgação de dados armazenados são potencialmente danosas. É necessário reconhecer, portanto, a possibilidade de danos que não são orgânicos e empiricamente mensuráveis.

Em terceiro lugar, mesmo que não tenha transgredido explicitamente o código ético vigente à época, o estudo feriu as sensibilidades éticas de muitos profissionais que sentiram que o respeito devido aos sujeitos de pesquisa havia sido violado. E, finalmente, o engano intencional, mesmo que fosse necessário ao desenho do estudo, não poderia se justificar se implicava possíveis danos ao participante. Enganar uma pessoa competente equivale a recrutar sem autorização pessoas de discernimento reduzido, pois em ambos os casos se atua na ausência da vontade informada do sujeito. Contudo, não faltou a defesa clássica do conseqüencialismo, reconhecendo que o engano é reprovável somente se causa dano importante, coisa que aqui não era o caso, e os desencargos do próprio Milgram, argumentando que seus participantes não tinham sofrido danos (Herrera 2001).

Aspectos éticos adicionais estão presentes em outro clássico exemplo de pesquisa imoral, que foi detectada vários anos depois de seu início. Sob o patrocínio do Serviço de Saúde Pública dos Estados Unidos, iniciouse, em 1932, a estudar o curso natural da sífilis em uma população afro-americana em Tuskegee, o que à época parecia plausível porque não existia tratamento que modificasse favoravelmente esse curso natural. Porém, quando na década de 1940 se obteve evidência do valor terapêutico da penicilina, um antibiótico barato e facilmente acessível, era óbvio que a ética clínica deveria se sobrepor à metodologia de pesquisa e proporcionar um tratamento capaz de curar a sífilis e reduzir suas complicações e letalidade. Contudo, o protocolo não foi modificado, nem se conseguiu interromper o estudo antes de 1972. Ou seja, durante 40 anos esse experimento foi conduzido e serviu de base para várias publicações científicas de grande impacto. A interrupção do estudo foi conseguida por esforços conjuntos de funcionários do próprio Serviço de Saúde Pública, dos meios de comunicação e da opinião pública (Caplan 1992).

O caso Tuskegee sofreu repúdio generalizado, mas também teve defensores, que empunharam a "falácia presentista" para reclamar que não se deveria medir o passado com critérios atuais (Benedek \& Erlen 1999). Não era lícito, segundo esses defensores, criticar a falta de consentimento informado, já que essa doutrina não existia em 1932. Finalmente, afirmou-se que grande parte dos participantes recebeu tratamento fora do protocolo, o que desmente a acuidade do projeto e invalida seus resultados por desvios do método. Restava, ainda, verificar a ausência de justificação dos riscos que a população recrutada para o estudo teve que suportar. $\mathrm{O}$ argumento freqüentemente utilizado de que oferecer placebos a populações pobres não significa lhes negar tratamento, já que elas nunca o tiveram, não é sustentado no caso Tuskegee, onde se considera eticamente imperativo que se tivesse introduzido a penicilina assim que ela estivesse disponível. Não se aceita, portanto, a desculpa de que seria coerente não dar o que nunca havia existido até então. Trata-se de um exemplo notório de inconsistência no pensamento ético, que não permite em Tuskegee o que se aceita na Tailândia.

Receberam especial atenção os experimentos indiscutivelmente imorais da inoculação do vírus da hepatite em crianças com retardo mental internadas na Escola Estatal de Willowbrook (Krugman et al. 1967) e da injeção de células cancerígenas em pacientes gravemente doentes hospitalizados no Hospital Judeu para Doenças Crônicas de Brooklyn (Langer 1966). Nesses estudos, ocorreram transgressões éticas múltiplas: recrutaram-se 
pessoas vulneráveis em sua competência mental, que estavam em situação de dependência - sujeitos confinados -, provocando-se nelas graves danos intencionalmente.

Foram publicados nessa época o artigo de Henry Beecher (1966) e o livro de Pappworth (1967), que detectaram com alarme o grande aumento de ensaios clínicos em seres humanos, a expansão dos orçamentos e a competitividade dos cientistas. Essas constatações os faziam temer que as incorreções éticas se tornassem mais freqüentes e sérias em uma época em que havia somente tentativas escassas de regular a pesquisa com seres humanos. Depois de apresentar 22 relatos de publicações de ensaios clínicos marcados por severas deficiências éticas, alguns deles resenhados nesse artigo, Beecher curiosamente termina com algumas recomendações gerais, como fortalecer o consentimento livre e esclarecido, ponderar benefícios e riscos e rejeitar a publicação em casos de transgressões severas; o autor se abstém, contudo, de opinar sobre a conveniência de instrumentos normativos formais ou de comentar a Declaração de Helsinque, promulgada pouco tempo antes.

O ocorrido na Alemanha, bem como os experimentos psicológicos realizados por Milgram em 1966 e, sobretudo, o amplamente debatido caso Tuskegee, abriram a discussão sobre a legitimidade de utilizar dados científicos obtidos por meio de ensaios eticamente questionáveis. Susan Reverby (2001) resgata o experimento recolhendo múltiplas formas artísticas, documentais, acadêmicas e políticas em que o episódio de Tuskegee se mostra frutífero para inspirar relatos de ficção com objetivos ideológicos. Tem-se dito, equivocadamente, que os participantes foram deliberadamente infectados pelos pesquisadores, que muitos receberam tratamento com penicilina por doenças intercorrentes porque se deslocavam para fora do âmbito do estudo e que o enfoque racial da pesquisa seria um caso típico de discriminação. A análise ética deve fazer uma abstração cuidadosa dessas polêmicas adicionais, uma vez que elas não relativizam a imoralidade do estudo, assim como o Holocausto não poderia se justificar dizendo que não afetou somente judeus e que os números alegados são exagerados.

Segundo alguns autores, a imoralidade dos experimentos proscreve a utilização de suas descobertas, sob pena de se levar os pesquisadores a pensar que os fins justificam os meios. Já de acordo com outros, os resultados de ensaios imorais devem ser ignorados em sinal de indignação ética e para desencorajar tais práticas. Argumenta-se que um trabalho deficiente no aspecto ético não tem validade científica, mas também se tem sugerido que esses casos sejam publicados com um comentário ético. A perspectiva pragmática vê a utilização da informação obtida como um reconhecimento de que o sacrifício dos participantes não foi totalmente em vão, ao passo que a perspectiva ética sanciona esses experimentos para desencorajá-los no futuro e porque, em adição à sua imoralidade, prestam-se a evasivas e distorções (Moe 1984).

De tempos em tempos volta a emergir a tentativa de resgatar descobertas científicas obtidas em condições eticamente contestáveis, argumentando-se que a ciência não deve ser julgada por sua imoralidade, mas apenas compadecer-se dela, ou que, não havendo dano, não há imoralidade (Proctor 2000). A Declaração de Helsinque de 1975 sugeriu que as pesquisas que violassem normas éticas não fossem publicadas. O conflito ainda não encontrou uma solução adequada, uma vez que continuam aparecendo pesquisas biomédicas com severas falhas éticas que são diversamente avaliadas. Exemplo disso é a renúncia obrigada de Marcia Angell, editora do New England Journal of Medicine, por ter questionado e rejeitado manuscritos eticamente discutíveis.

\section{As primeiras diretrizes sobre ética em pesquisa}

Com o notável aumento da atividade científica, sobretudo na área biomédica, tornou-se logo evidente que se devia elaborar uma regulamentação ética mais completa que a oferecida pelo Código de Nurembergue. Tanto Nurembergue como Helsinque foram compreendidos como documentos de ordem ética, porém legalista. A Declaração de Helsinque foi considerada mais útil e mais ampla, principalmente por sua preocupação com o consentimento informado dos participantes ou de seus representantes legais, no caso de pessoas incapazes, e com a distinção entre ensaios terapêuticos e não-terapêuticos.

O Código de Nurembergue ficou conhecido como um documento reativo e acusador, cujo efeito prospectivo foi muito atenuado, o que explica a imediata criação de grupos de estudo no interior da Associação Médica Mundial (AMM). Os grupos apresentaram, em rápida sucessão, uma Resolução sobre Experimentação Humana, em 1953, um Guia para Pesquisadores, em 1955, e um Código Ético para Pesquisadores. Explorando a literatura, constata-se que um rascunho da Declaração de Helsinque do ano de 1962 prescrevia a inclusão, como participantes, de prisioneiros de guerra, civis detidos durante ocupações militares, pessoas encarceradas e indivíduos mentalmente incapazes de dar consentimento livre e esclarecido válido.

As deliberações da AMM culminaram em 1964, com a Declaração de Helsinque, inaugurando a análise acadêmica, posteriormente assumida pela bioética, da probidade de pesquisas biomédicas. Desde o começo, a declaração se viu enfrentada pela desconfiança dos cientistas perante regulações minuciosas que produziriam sérias limitações à liberdade dos pesquisadores e não lhes permitiriam sua própria reflexão sobre a possibilidade de dispensar o consentimento informado do paciente ou de realizar estudos em crianças ou adultos mentalmente incapazes - todas as situações que a AMM propunha desautorizar.

A oposição ao Código de Nurembergue que precedeu a Declaração de Helsinque partiu de Hill (1963), um dos mais reputados estatísticos da época, que se mostrou cético em relação à idéia de que as diversas formas de pesquisa clínica pudessem ser reguladas por um mesmo código. Suas propostas mantêm o espírito do código, 
mas evitam a aplicação normativa, preferindo a decisão situacional e recomendando recorrer ao consentimento informado somente se os dois grupos do ensaio controlado são desiguais no tocante a riscos e benefícios, bem como utilizar placebos unicamente se não há tratamento útil com o qual comparar o novo princípio ativo. Hill insiste que a todo momento as obrigações éticas se antepõem ao experimental, uma premissa que atualmente se expressaria afirmando-se que a ética clínica há de primar sobre a ética em pesquisa.

Simultaneamente à promulgação da Declaração de Helsinque, publica-se um documento do Conselho Britânico de Pesquisa Médica afirmando enfaticamente que o estudo de um novo procedimento médico deve ser comparado com o melhor método em uso, o que descarta o emprego de placebos, a menos que ainda não exista uma terapia eficaz. O consentimento informado, especialmente em ensaios não-terapêuticos, deveria emanar de uma relação interpessoal apoiada, mas não substituída, por um documento assinado. Quando as pessoas carecem da competência para dar seu consentimento, não devem ser recrutadas para pesquisas não-terapêuticas que tragam algum tipo de risco. O teor do documento britânico se assemelha muito ao da Declaração de Helsinque, ambos sendo muito claros em antepor a proteção dos indivíduos aos interesses da ciência ou da sociedade, e situando-se como defensores das pessoas incapazes de exercer sua vontade. A revisão da Declaração de Helsinque em 1975, ao reforçar o caráter fundamental do consentimento informado, institui a necessidade de criar comitês de ética em pesquisa e aconselha não publicar trabalhos de proveniência eticamente objetável.

A ênfase do Código de Nurembergue no consentimento voluntário é acolhida na Declaração de Helsinque, já com a linguagem mais refinada do consentimento informado. Sobre a proteção aos participantes, principalmente se eles carecem da competência mental necessária para poder consentir de forma livre e esclarecida, a Declaração de Helsinque recomenda que os ensaios clínicos façam clara distinção entre estudos terapêuticos - que têm expectativas de desenvolver uma melhoria terapêutica para os pacientes envolvidos - e não-terapêuticos, direcionados a objetivos que nada têm a ver com a condição médica dos pacientes-participantes selecionados. É compreensível que os riscos que os participantes podem correr nos estudos terapêuticos sejam mais aceitáveis, por haver expectativas de benefícios diretos. Conseqüentemente, na impossibilidade de obter um consentimento informado, infere-se que o participante não poderá ser recrutado para estudos não-terapêuticos que não o beneficiam, mas o fazem correr riscos desnecessários.

\section{O Relatório Belmont e o principialismo bioético}

Poucas vezes se fez notar a encruzilhada no caminho da ética em pesquisa que significou o Relatório Belmont (1978), certamente o marco mais relevante nessa área durante a década de 1970. O documento estabeleceu uma clara distinção entre a trajetória seguida pela ética em pesquisa nos Estados Unidos e sua evolução no restante dos países, distinção esta que terminaria sob franco debate a partir da Declaração de Helsinque, revisada no ano 2000.

O Relatório Belmont é o resultado das deliberações da Comissão Nacional para a Proteção de Sujeitos Humanos em Pesquisas Biomédicas e Comportamentais (1974-1978) e da Comissão Consultiva Nacional de Bioética (NBAC), estabelecida em 1995 e 1996 com o propósito de revisar, ratificar e unificar esforços anteriores no campo. Essas são duas das várias comissões ad hoc que o Executivo estadunidense criou para estudar problemas e propor linhas de ação em um âmbito social específico. O Relatório Belmont introduz intencionalmente a linguagem dos princípios éticos ao exigir que toda pesquisa seja respeitosa com as pessoas, benéfica para a sociedade e equânime em seu balanço entre riscos e benefícios. Desde o começo, lamentou-se a ausência de um quarto princípio que incorporasse a dimensão comunitária, desencadeando um debate de duas faces que ainda perdura (Childress 2000).

O Relatório Belmont foi o campo fértil da bioética principialista dominante em grande parte do mundo ocidental, e não é de estranhar que o debate sobre ética em pesquisa tenha seguido as feições dos quatro princípios do grupo da Universidade de Georgetown, em uma expansão retórica que produziu muitas variantes e não poucas polêmicas. Houve uma série de comissões nacionais que se encarregaram de temas específicos de bioética e estabeleceram para a ética em pesquisa algumas linhas gerais de reflexão, incluindo a incorporação da opinião pública, o desenvolvimento, a estruturação e o controle dos comitês institucionais de revisão ética (institutional review boards, em língua inglesa), que têm servido de modelo aos comitês de ética em pesquisa em outros países. Uma preocupação permanente tem sido a incorporação de participantes com a chamada "incapacidade decisória”, ou seja, com competência mental reduzida que os impede de participar plenamente do processo de consentimento livre e esclarecido.

É possivelmente no enfrentamento entre os interesses da ciência e os valores do ser humano que mais bem se percebe a virada que a ética em pesquisa tem sofrido desde meados do século XX. Essa virada teve início com a crítica de Leon Kass (1990) ao excesso de teoria ética e ao insuficiente respeito pela Declaração de Helsinque no tocante ao consentimento informado, bem como na insistência adicional formulada em 1972 por Jay Katz (1993) de se observar um respeito especialmente cuidadoso pela autonomia quando se solicita o consentimento informado para pesquisas que não serão benéficas ao participante. O respeito pela autonomia foi durante muito tempo suficientemente robusto para exigir que qualquer desgaste iniciado por interesses comunitários fosse claramente justificado (Childress 1990); contudo, fez-se a sutil distinção de codificar princípios segundo uma ordem de prioridade e de apresentação, concedendo primeiro lugar à autonomia (Childress 2000). Segundo Katz, um protocolo de pesquisa deve cumprir uma série de condições, 
como avaliar possíveis riscos e ponderá-los em relação a eventuais benefícios, além de respeitar a equanimidade na seleção de participantes, antes de ser submetido à consideração sobre o consentimento informado dos sujeitos cuja participação se solicita. De certa forma, a autonomia já vem protegida por essas condições prévias.

Como bruxos aprendizes, seus defensores viram crescer o desejo de autonomia a ponto de esquecer a problematização de John Stuart Mill, segundo a qual a liberdade somente se limita quando interfere na liberdade dos outros, condição necessária para uma convivência equânime. Foi preciso haver um retrocesso na celebração irrestrita da autonomia, começando por solicitar sua limitação em prol de uma ética social engajada em uma ordem justa (Veatch 1984; Callahan 1984). Nos anos em que Henry Beecher criticava a qualidade moral de muitas pesquisas, Kass (1990) e Katz (1993), que concordavam sobre a importância da autonomia, discutiam a melhor forma de defendê-la: enquanto o primeiro enfatizava o amadurecimento moral dos cientistas para além do excesso de teoria bioética, o segundo respondia que a reflexão teórica é indispensável e deve levar a uma clara distinção entre a prática médica e a pesquisa biomédica, afirmando ainda que esta apenas excepcional e justificadamente deve exigir dos indivíduos que participem de ensaios cujos fins lhes são alheios.

Sensível às críticas, a própria bioética principialista começou a desgastar o princípio inicialmente sacrossanto da autonomia, sobretudo em relação a situações clínicas especiais, a sujeitos de competência mental comprometida e, especialmente, no mundo dos participantes de pesquisa (Kottow 2004). Para se chegar ao enfraquecimento da autonomia, foi preciso realizar um trabalho teórico destinado a invalidar a diferença entre ensaios terapêuticos e não-terapêuticos e insistir na distinção entre ética em pesquisa e ética clínica, a fim de abandonar os compromissos com o participante como paciente, submetendo-o à orfandade terapêutica de modo a mais bem depurar a farmacodinâmica do estudo. Além disso, ofuscou-se o conceito de benefícios para criar objetivos e valores científicos fictícios de mais fácil manejo retórico, como "avanço do conhecimento", "bem social" ou "benefício para gerações futuras".

As polêmicas que precederam a mais recente Declaração de Helsinque (Edimburgo 2000) marcaram o início de profundas discrepâncias entre interesses criados, de um lado, e defensores de uma ética em pesquisa rigorosamente comprometida com a proteção irrestrita dos direitos de pacientes, de participantes, de indivíduos vulneráveis e de comunidades indefesas, de outro. Os desacordos se aprofundam e tendem a favorecer os mais poderosos, de modo que se cria uma convergência assimétrica na qual a posição de pesquisadores e patrocinadores predomina sobre a proteção das pessoas.

As declarações da Associação Médica Mundial são as normas mais conhecidas, mas não as únicas que tentam regular a atividade científica, sobretudo no âmbito biomédico; existem, além delas, as normas do Conselho de Organizações Internacionais de Ciências Médicas
(CIOMS/OMS) e do Conselho Nuffield de Bioética, os documentos do Conselho Europeu e diversas declarações voltadas para assuntos específicos, como pesquisa em embriões ou em material genético e estudos epidemiológicos. Em linhas gerais, eles exibem grandes coincidências na intenção de proteger pacientes, participantes e comunidades, mas com uma tendência cada vez mais notória de respeitar os interesses de pesquisadores e patrocinadores e de ceder ao desejo de mercantilizar conhecimentos, procedimentos e produtos, em conformidade com a polarização 90:10 da pesquisa - 90\% dos recursos destinam-se ao estudo de somente 10\% das doenças que afetam as sociedades abastadas. Na América Latina, o referencial mais utilizado continua sendo a Declaração de Helsinque, tanto porque continua compromissado em proteger os pacientes e participantes como porque mantém um formato de fácil consulta.

\section{Os comitês de ética em pesquisa}

Tanto a Declaração de Helsinque (1975) quanto o Relatório Belmont (1978) insistiram na necessidade de criar instâncias diretamente relacionadas com as atividades científicas. Tais instâncias adaptariam a linguagem propositiva, mas escassamente vinculante, dos documentos declaratórios, a fim de regular todos os aspectos bioéticos das pesquisas em seres vivos, em especial os estudos com seres humanos. Citando muito brevemente, os comitês de ética em pesquisa foram desenvolvendo as seguintes características:

- diferem dos comitês de ética hospitalar em sua composição, suas funções e suas normas;

- não são compostos somente de cientistas naturais, incluindo representantes das disciplinas sociais e da comunidade;

- a participação de outros profissionais ou membros da comunidade não se rege por um princípio de representatividade, mas sim de idoneidade;

- seguindo o modelo dos comitês institucionais de revisão ética, prefere-se o comitê de ética local, que conhece sua própria instituição e seus pesquisadores, podendo convocá-los com mais facilidade para levar adiante a pesquisa;

- os comitês de ética em pesquisa são duplamente obrigatórios: toda pesquisa deve ser revisada por eles, e todo pesquisador deve acatar as correções éticas que o comitê exigir;

- a deliberação do comitê de ética em pesquisa não apenas garante a conformidade com normas gerais como também analisa individualmente cada protocolo;

- os comitês de ética em pesquisa asseguram o consentimento livre e esclarecido, a proporcionalidade dos riscos, os detalhes do método científico que possam incidir em riscos, os aspectos econômicos que velam pela probidade e a utilização pertinente dos resultados;

- os comitês de ética em pesquisa devem funcionar de forma regulamentada e documentada, tanto para fundamentar suas deliberações quanto para criar jurisprudência. 
A profusão de estudos científicos na área biomédica tem intensificado enormemente a carga de trabalho dos comitês de ética em pesquisa, fazendo com que eles despachem seus relatórios de forma apressada e rotineira. Diante dessa crise, diversos países estão criando instâncias de controle dos trabalhos dos comitês e poupandoos de analisar projetos críticos, como os genéticos, os étnicos e os de fronteira no âmbito da biotecnociência e da nanotecnologia. Exemplo pioneiro disso é a Comissão Nacional de Ética em Pesquisa (Conep). Uma iniciativa similar havia sido sugerida por Katz (1993), no sentido de antepor uma comissão nacional aos comitês de ética em pesquisa, pois o autor suspeitava que estes se sentiam mais comprometidos em proteger os interesses de sua instituição que os sujeitos de pesquisa.

\section{Limitações à atividade científica}

Ao longo da história, a atividade científica insistiu em sua inocência e boa vontade, que tornariam supérflua toda interferência moral ou restrição de sua liberdade. Essa imunidade ficou difícil de sustentar na medida em que os cientistas participam de projetos militares, invadem fronteiras críticas do saber - genética, nanotecnologia - ou escolhem áreas e temas de pesquisa por serem economicamente promissores. As respostas oficiais em diversas nações têm sido ceder a pressões da sociedade civil e proporcionar o controle ético mediante proibição ou negativa de financiamento público a pesquisas em animais não-humanos, ao uso de células embrionárias, à clonagem reprodutiva ou a outras áreas moralmente críticas.

Uma iniciativa de auto-regulação foi propiciada a partir da Conferência de Asilomar, em 1975, em que um grupo de proeminentes cientistas concluiu que os riscos de certos estudos de DNA recombinante sugeriam uma moratória que suspendia alguns experimentos, ao passo que outros podiam prosseguir sob medidas de estrita cautela. A moratória não foi longa nem absoluta, nem tampouco houve controle ferrenho em respeitá-la, mas parece ter mostrado que os pesquisadores estão dispostos a regular suas atividades por razões éticas, mesmo que outros tenham chegado a conclusões opostas, de que a ciência não seria capaz de moderar sua atividade. $\mathrm{Na}$ atualidade se vive uma moratória em torno da pesquisa sobre clonagem reprodutiva, mas é óbvio para todos que a fiscalização dessa proibição é impossível, mesmo quando apoiada por uma legislação restritiva.

\section{Temas pendentes}

O procedimento de obtenção do consentimento livre e esclarecido tem se transformado, passando de um processo de deliberação conjunta entre pesquisador e participante à assinatura de um documento que mal resume ou substitui o que deveria ter sido uma comunicação pessoal. Os comitês de ética em pesquisa cometem o erro de analisar esse documento, em muitas ocasiões preparado ao modo de um formulário inespecífico, como se fosse o fiel testemunho da informação concedida. As sucessivas revisões da Declaração de Helsinque desgas- taram acentuadamente o consentimento informado, especialmente no caso de pessoas que não podem exercêlo de forma plena.

Quando se completaram cinqüenta anos da promulgação do Código de Nurembergue, os Médicos para a Prevenção da Guerra Nuclear apresentaram o Código de Nurembergue de 1997, ratificando a autonomia individual e o consentimento livre e esclarecido, e ao mesmo tempo criticando a relativização e degradação desse princípio desde o código de 1947. A pesquisa biomédica sempre deve estar destinada a pessoas concretas, e a proteção dos direitos humanos, bem como do princípio do consentimento livre e esclarecido, não deve ceder diante de supostos interesses superiores, mesmo que com isso se atrase a pesquisa. A qualidade da defesa dos direitos humanos e da autonomia se mede pelo trato que se dá a indivíduos incapazes de consentir, os quais devem ser protegidos de toda pesquisa que só beneficie a outros (Wunder 2000).

A posição do Código de Nurembergue de 1997 se apresenta como uma crítica em um âmbito notoriamente mais propenso a facilitar os trabalhos dos pesquisadores, à custa de reduzir a proteção dos participantes. O Conselho da Europa proclamou a Convenção sobre Direitos Humanos e Biomedicina (1997), cujos traços essenciais estabelecem que a pesquisa com seres humanos somente ocorra quando não for substituível por outro método de obtenção do conhecimento desejado, que os riscos sejam razoáveis, que haja avaliação e aprovação tanto científica quanto ética e, sobretudo, que se busque um consentimento livre, claro, específico e documentado. A experimentação com indivíduos incapazes de dar consentimento voluntário é severamente limitada, mas não proscrita, havendo cláusulas de escape que permitem incorporá-los mesmo que o ensaio não seja em seu direto benefício (Manuel 2000). A convenção não é vinculante, e os países europeus aderem parcial ou totalmente a seus artigos ou desenvolvem normas sobre aspectos não contemplados por ela, o que na França, por exemplo, se interpretou como a liberdade de pesquisar, sujeita a condições estritas sobretudo em relação a participantes de consentimento impossível ou frágil (Amiel et al. 2001).

O marco mais recente na ética em pesquisa foi a promulgação da Declaração Universal sobre Bioética e Direitos Humanos (2005). A declaração tem suscitado diversas reações, desde ser celebrada como um documento que indica novos rumos para a ética até gerar opiniões muito negativas a respeito da confusão de conceitos e da banalidade de asseverações que contém. No tocante à ética em pesquisa, há de se reconhecer que a declaração parece precipitada para uma disciplina ainda insuficientemente solidificada, já que não conseguiu elaborar os temas para além de sua apresentação na Declaração de Helsinque (2000). No máximo, ratifica com a flacidez de sua linguagem e com o uso predominante do condicional que "deveriam" ser considerados os interesses das comunidades, bem como dos vulneráveis e dos mentalmente incapazes. 
Houve uma diluição do sentido originário da pesquisa biomédica, orientada a obter benefícios terapêuticos reais, não simplesmente modificações marginais do que já existe. Os protocolos se gabam, na atualidade, de negar toda intenção de benefício aos participantes e se protegem com fórmulas vazias, como bem social, futuros benefícios e aumento de conhecimentos, por trás das quais se escondem interesses acadêmicos ou econômicos carentes de qualquer horizonte social. Com o mesmo argumento do suposto benefício geral, rompe-se a barreira que eximia as pessoas vulneráveis de serem recrutadas, a menos que fosse para seu benefício direto e com riscos aceitavelmente limitados. Agora, argumenta-se que essas populações devem ser incorporadas para que não se exclua sua patologia de ser investigada, contornandose com isso as normas éticas que somente permitem o recrutamento de pessoas vulneráveis quando a pesquisa tem claras intenções terapêuticas para elas.

Uma confusão parecida ocorre na polêmica sobre tratamentos de emergência em sujeitos inconscientes sem que haja um responsável presente, entre tratamentos experimentais (quando é o único existente) e a pesquisa em situações clínicas críticas (quando se comparam alternativas). Tem-se argumentado a favor de aceitar o critério do pesquisador para tomar a decisão de iniciar um estudo experimental nessas situações (Truog 1999). Em prol da proteção devida aos sujeitos, a pesquisa somente deveria ser aceita se cumpridas três condições: a) não há acesso razoável à decisão de um responsável nem se conhece um posicionamento expresso anteriormente pelo paciente; b) o tratamento existente tem sérias deficiências de efetividade e/ou de complicações; c) o tratamento experimental tem expectativas razoáveis e fundamentadas de melhorar o prognóstico.

A ética em pesquisa deverá encarar um tema até agora timidamente evitado sob o conceito de que ciência e economia não se misturam, uma idéia que já se tornou completamente obsoleta. O motor contemporâneo da atividade científica é o lucro, a conquista de nichos de mercado, a competitividade, a obtenção de patentes. A curiosidade foi substituída pelo pragmatismo, em um clima em que pesquisadores, patrocinadores e instituições científicas cuidam de seus respectivos interesses, ao mesmo tempo em que fomentam o recrutamento de participantes altruístas que assumem riscos, mas não recebem benefícios por sua participação. É ilustrativo de uma confusão de interesses que uma iniciativa biológica como o Projeto Genoma Humano tenha nascido sob a guarda do Departamento de Energia dos EUA, o qual é responsável pelos programas nucleares desse país.

Qualquer pagamento que exceda um mínimo é considerado incentivo indevido, desconhecendo-se que os participantes são um meio para que outros obtenham benefícios não criticados como desmedidos. Esse menosprezo pelo participante adquire traços perversos quando se propõe fazer da participação em pesquisas um dever cívico que todo cidadão tem de cumprir em prol do bem público (Rhodes 2005). Da Comissão Presidencial dos EUA provém a sugestão, inicialmente pensada para crianças, mas logo ampliada para adultos, de utilizar uma "ladeira escorregadia de riscos/benefícios": quanto mais riscos ou benefícios para as pessoas, mais exigente tem de ser o nível de competência requerido para aceitar ou recusar a pesquisa e, ao contrário, se a intervenção tem menos conseqüências, seriam aceitas decisões tomadas desde níveis de discernimento mais baixos. Ainda que tenha sua lógica, a regra é inquietante na medida em que impede as pessoas de tomar decisões mais importantes para si.

A regra descrita deita sua sombra sobre uma relação entre riscos e incentivos que tem sido motivo de polêmica. Os que são contra incentivos argumentam que seria totalmente inadequado oferecer incentivos importantes para estimular os possíveis participantes a ingressar em estudos de altos riscos. Não obstante, o aspecto indevido dos incentivos não está em aceitá-los, mas em oferecêlos em troca de assumir riscos que, sem eles, seriam inadmissíveis. Tais riscos devem ser rechaçados como desproporcionais, haja ou não incentivos.

Outra estratégia retórica que procura facilitar aos pesquisadores incluírem participantes desprovidos do poder de discernimento para opinar é a definição de risco mínimo, que, pela sua insignificância, poderia ser imposto a sujeitos carentes de vontade autônoma (Wendler 2005). Uma definição de risco mínimo o iguala aos riscos cotidianos; outra o pensa como equivalente à rotina médica a que o participante se submete. Ambas são definições ad hoc dificilmente aceitáveis para uma bioética preocupada com o amparo de sujeitos vulneráveis, como deve ser a bioética latino-americana (Kottow 2005).

\section{A bioética dos países em desenvolvimento}

Em relação à bioética do Hemisfério Sul, pode-se dizer que a pesquisa biomédica está sendo desviada para países em desenvolvimento por razões pragmáticas, que contemplam benefícios desproporcionalmente maiores para nações patrocinadoras que para países anfitriões. Ao mesmo tempo, desenvolve-se uma defesa retórica para minimizar as acusações de exploração (Hawkins \& Emanuel 2005). O lado mais influente da argumentação bioética acadêmica e da elaboração de normas internacionais tende a relativizar a proteção de participantes e pacientes, com colocações cuja linguagem imprecisa esconde uma tolerância de fundo a favor das preferências dos grandes interesses.

Essa tendência se vê claramente na polêmica que gerou a mais recente Declaração de Helsinque, controvérsia esta ilustrada pelos adendos introduzidos por pesquisadores mais interessados na ciência que nos sujeitos de pesquisa e pelas publicações com que tais adendos foram confirmados. O objetivo dessas revisões é defender o uso de placebos, negar a garantia de benefícios pós-pesquisa e justificar a falta de compromisso com as necessidades de comunidades que abrigam essas pesquisas.

A bioética dos países em desenvolvimento necessita de um caminho robusto que reconheça, defina e indique claramente as práticas impróprias e as transgressões à ética em pesquisa, como a exploração, a coerção, a 
manipulação do consentimento livre e esclarecido, o enfraquecimento de compromissos beneficentes, a orfandade terapêutica ao usar pacientes como participantes e a utilização de pessoas vulneráveis em pesquisas nãoterapêuticas cujo destino é servir a interesses comerciais. Vulnerabilidade, exploração, coerção e manipulação são todos temas que têm protagonizado fortes polêmicas e merecem ser estudados em detalhes.

O assunto excede os limites deste artigo, mas convém chamar a atenção para uma estratégia retórica que define essas diversas imposições autoritárias de uma maneira tão exata que grande parte das práticas em uso consegue ser moralmente eximida. Essa mesma facilidade de desencargo praticada pela bioética dos países desenvolvidos precisa ser analisada sob a perspectiva dos afetados, pois um olhar atento e sensível detecta que se explora e se coage de uma forma sutil, que oculta os danos produzidos. O uso liberal da vulnerabilidade, que é um conceito que denota fragilidade, mas não dano, quando se está lidando com indivíduos e populações vulneráveis esconde a despreocupação com o enfraquecimento dos países anfitriões, nos quais são realizadas as pesquisas sem oferecer os cuidados requeridos para a maioria das situações (Kottow 2003).

As diretrizes internacionais sobre ética em pesquisa apresentadas neste artigo devem fundamentar as ações não apenas dos pesquisadores, mas também dos patrocinadores e organizadores de pesquisas. Essa é uma forma de assegurar a dignidade dos participantes e de aproximar os direitos humanos à ciência. Os passos para uma pesquisa científica incluem uma coerência moral por parte da equipe investigadora, bem como exigem revisões detalhadas por parte das agências reguladoras de cada país. O avanço da ciência tem trazido conquistas importantes para o bem-estar das pessoas, porém, esses ganhos em qualidade de vida não podem ser alcançados à custa da dignidade dos participantes de pesquisa e da integridade da comunidade científica.

\section{Nota}

1. N.T. A denominação consentimento informado, utilizada nos documentos internacionais sobre ética em pesquisa e na descrição das pesquisas realizadas no contexto internacional, corresponde na regulamentação brasileira ao termo consentimento livre e esclarecido.

\section{Referências bibliográficas}

Amiel P, Mathieu S, Fagot-Largeault A. Acculturating human experimentation: an empirical survey in France. J Med Philos. 2001; 26:285-298.

Anders G. Die antiquiertheit des menschen I. München: C. H. Beck; 2002.

Beecher HK. Ethics and clinical research. New England J Med. 1966; 274(24):1354-60.

Benedek TG, Erlen J. The scientific environment of the Tuskegee study of syphilis, 1920-1960. Perspec Biol Med. 1999; 43:1-30.
Binding K, Hoche A. Die freigabe der vernichtung lebensunwerten lebens, ihr mass und ihre form. Leipzig: [s.n.]; 1920.

Burt RA. The suppressed legacy of Nüremberg. Hastings Center Report. 1996; 26(5):30-3.

Callahan D. Autonomy: a moral good, not a moral obsession. Hastings Center Report. 1984; 14(5):40-2.

Caplan AL. Twenty years after. The legacy of the Tuskegee syphilis study. Hastings Center Report. 1992; 22(6):29-32.

Childress JF. The place of autonomy in bioethics. Hastings Center Report. 1990; 20(1): 12-17.

Childress JF. Nüremberg's legacy: some ethical reflections. Perspec Biol Med. 2000: 43(3):347-61.

Dworkin R. Sovereign virtue. Cambridge: Harvard University Press; 2000.

Faden R. The Advisory Committee on Human Radiation Experiments: reflections on a presidential commission. Hastings Center Report. 1996; 26(5):5-10.

Habermas J. Die zukunft der menschlichen natur. Frankfurt aM.: Suhrkamp; 2001.

Hawkins JS, Emanuel EJ. Clarifying confusions about coercion. Hastings Center Report. 2005; 35(5):16-9.

Herrera CD. Ethics, deception, and "those Milgram experiments”. J Appl Philos. 2001; 18(3): 245-56.

Hill AB. Medical ethics and controlled trials. Brit Med J. 1963; 1(5337): 1043-9.

Ivy AC. Nazi war crimes of a medical nature. Fed Bull. 1947; 33:133-46. Reproduzido em: Reiser SJ, Dyck AJ, Curran WJ, editores. Ethics in medicine. Cambridge: MIT Press; 1977: 267-72.

Jonas H. Das prinzip verantwortung. Frankfurt aM.: Suhrkamp; 1984.

Kass LR. Practicing ethics: where's the action? Hastings Center Report. 1990; 20(1): 5-12.

Katz J. Ethics and clinical research revisited. Hastings Center Report. 1993; 23(5): 31-9.

Kottow M. The vulnerable and the susceptible. Bioethics. 2003; 17(5-6):460-71.

Kottow M. The battering of informed consent. J Med Ethics. 2004; 30(6): 565-9.

Kottow M. Bioética de proteção: considerações sobre o contexto latino-americano. In: Schramm FR, Rego S, Braz $\mathrm{M}$ et al., editores. Bioética, riscos e proteção. Rio de Janeiro: UFRJ, Fiocruz, 2005; p. 29-44.

Kottow M. Ética de protección. Bogotá: Unibiblos; 2006.

Kottow MH. Should medical ethics justify violence? J Med Ethics. 2006; 32(8): 464-7.

Krugman S, Giles JP, Hammond J. Infectious hepatitis: evidence for two distinctive clinical, epidemiological, 
and immunological types of infection. JAMA. 1967; 200(5): 365-73.

Langer E. Human experimentation: New York verdict affirms patient's rights. Science. 1966; 151(3711): 663-6.

Macintyre A. After virtue. 2. ed. Notre Dame: University of Notre Dame; 1984.

Manuel C. Les législations nationales européennes s'accordent-elles avec la nouvelle convention sur les droits de l'homme et la biomédecine? In: Rendtorff JD, Kemp P, editores. Basic ethical principles in European bioethics and biolaw. Barcelona: Institut Borja de Bioètica; 2000:173-93.

Milgram S. Behavioral study of obedience. J Abnormal Psychol. 1963; 67:371-8.

Mitscherlich A, Mielke F. Medizin ohne menschlichkeit. Frankfurt aM: [s.n.]; 1978.

Moe K. Should the nazi research data be cited?. Hastings Center Report. 1984; 14(6):5-7.

Moreno JD. The only feasible means: the Pentagon's ambivalent relationship with the Nüremberg Code. Hastings Center Report. 1996; 26(5):11-9.

Pappworth MH. Human guinea pigs: experimentation on man. London: RKP; 1967.

Proctor RN. Nazi science and nazi medical ethics: some myths and misconceptions. Perspec Biol Med. 2000; 43(3): 335-46.
Reverby SM. More than fact and fiction. Hastings Center Report. 2001; 31(5): 22-8.

Rhodes R. Rethinking research ethics. Am J Bioethics. 2005; 5(1): 7-28.

Sass H-M. Rundschreiben: Pre-Nüremberg German regulations concerning new therapy and human experimentation. J Med Philos. 1983; 8(2): 99-111.

Schafer A. Biomedical conflicts of interest: a defense of the sequestration thesis - learning from the cases of Nancy Olivieri and David Healy. J Med Ethics. 2004; 30:8-24.

Schafer A. Commentary: science scandal or ethical scandal? Olivieri redux. Bioethics. 2007; 21 (2):111-5.

Truog RD. Informed consent and research design in critical care medicine. Critical care. 1999; 3: 29-33.

Veatch RM. Autonomy's temporary triumph. Hastings Center Report. 1984; 14(5):38-0.

Wendler D. Protecting subjects who cannot give consent: toward a better standard for "minimal" risks. Hastings Center Report. 2005; 35(5):37-43.

Wunder M. Medicine and conscience: the debate on medical ethics and research in Germany 50 years after Nüremberg. Perspec Biol Med. 2000; 43(3):373-81.

\section{Sobre o autor}

\section{Miguel Kottow}

Miguel Kottow é professor da Escola de Saúde Pública e Departamento de Bioética e Humanidades da Universidade do Chile, Santiago, Chile. Médico cirurgião especializado em oftalmologia. Doutor em medicina, mestre em sociologia, professor titular da Universidade do Chile, Membro do comitê de redação de diversas revistas internacionais, autor de numerosos artigos sobre oftalmologia, bioética, medicina e ciências humanas. Autor de vários livros. Membro do Conselho Diretor da Redbioética/Unesco (2003-2007). Membro do Comitê Diretivo da Sociedade Internacional de Bioética (Sibi), seção da America Latina (2003-2007). 